\title{
Conditioned olfactory aversion in the male Mongolian gerbil
}

\author{
TERRY F. PETTIJOHN \\ Ohio State University, Marion, Ohio 43302
}

\begin{abstract}
Two experiments were conducted to investigate conditioned aversion to the odor of phenylacetic acid in the male Mongolian gerbil (Meriones unguiculatus). In Experiment 1, 60 subjects were exposed to a cotton swab coated with phenylacetic acid placed in the center of a 1 -m-square open field for two 5 -min sessions $48 \mathrm{~h}$ apart. Half of the subjects received an injection of $\mathrm{LiCl}$ immediately after Session 1 , while the rest received saline. The $\mathrm{LiCl}$ subjects quickly learned to avoid the phenylacetic acid in Session 2 , as demonstrated by significantly $(\mathrm{p}<.01)$ lower investigation time and frequency of approach, and longer latency to contact. In Experiment 2, 30 subjects were exposed to a clean cotton swab, and did not show any conditioned aversion. This research demonstrated that the conditioned aversion paradigm can be extended to olfactory aversion to phenylacetic acid in male gerbils.
\end{abstract}

Wilson (1970) has suggested that one of the primary functions of animal pheromones in social species may be individual recognition. A variety of studies have demonstrated the ability of Mongolian gerbils to identify relevant social odors. Dagg and Windsor (1971) found that young gerbils could be trained in a T-maze to discriminate between various conspecific urine odors. Halpin (1974) extended their work by showing that male gerbils were capable of discriminating between individual male gerbil urine and ventral gland odors, suggesting a function of individual recognition. Pettijohn (1977) found that urine conveyed information on sexual identity and sexual readiness to the male gerbil.

Mongolian gerbils show a great deal of ventral marking, which might be important in social communication. Marking behavior has been associated with dominance, territoriality, and exploration (Thiessen, Blum, \& Lindzey, 1969). Thiessen, Regnier, Rice, Goodwin, Isaacks, and Lawson (1974) have identified a ventral scent-marking phermone in the male Mongolian gerbil as phenylacetic acid. They found gerbils investigated both ventral gland sebum and phenylacetic acid more than control substances.

It has been shown that many species of animals can rapidly learn to avoid certain tastes when the tasted substance is followed by gastrointestinal illness induced by administration of a toxic sub-

This research was supported by a faculty research grant from the Ohio State University College of Social and Behavioral Sciences. The author would like to thank Debby Merritt for assistance in the data collection. Portions of the data were presented at the 1979 meeting of the Midwestern Psychological Association in Chicago. Send reprint requests to: Terry F. Pettijohn, Department of Psychology, The Ohio State University, Marion, Ohio 43302. stance (Riley \& Baril, 1976). Research has also shown that animals can learn aversion to particular odors when they are paired with illness (Rudy \& Cheatle, 1977; Supark, Macrides, \& Chorover, 1971). Emmerick and Snowdon (1976) reported that lithium-chlorideinduced illness was unable to modify mating in male hamsters when the stimulus was an estrous female, but that when made ill after being exposed to phenylacetic acid odor, the subjects showed longer latencies in initiation of mating with a female coated with the test substance.

The current study attempted to determine whether the conditioned aversion paradigm could be extended to olfactory aversion in the male Mongolian gerbil. Since the gerbil has been shown to be able to quickly learn taste aversions (Kanarek, Adams, \& Mayer, 1975) and the gerbil used olfactory cues in social recognition (Halpin, 1974), it was predicted that it would be possible to condition the gerbil to avoid phenylacetic acid (a gerbil ventral scent marking pheromone) if, after a brief exposure, the subject was made to experience a gastrointestinal illness before retesting.

\section{EXPERIMENT 1}

\section{Method}

Subjects. The subjects for this experiment consisted of 60 adult, experimentally naive male Mongolian gerbils (Meriones unguiculatus), approximately 12 months old at testing. All subjects were group reared in large opaque plastic laboratory cages $(48 \times 27 \times 20 \mathrm{~cm})$. Prior to the beginning of the study, all subjects were isolated in small plastic laboratory cages $(20 \times$ $30 \times 20 \mathrm{~cm}$ ). Wood-chip bedding covered the cage floor, and Purina Lab Chow and water were continuously available. The laboratory room temperature was $23^{\circ} \mathrm{C}$.

Apparatus. All subjects were tested in a 1-m-square open field painted white on the inside. Lines on the floor marked off $5-\mathrm{cm}$ sections in the open field. The phenylacetic acid was placed on 
the tip of a 6-cm swab by dipping the water-moistened tip of the swab into the phenylacetic acid crystals, so that aproximately $1 \mathrm{mg}$ of the chemical was on the cotton tip (this concentration was much greater than natural levels). The cotton swab was inserted in the center of the top of a 5-cm cube of fresh modeling clay so that only the cotton tip protruded out of the top of the clay. The clay was then placed in the center of the open field. The experimenter wore clean rubber gloves whenever handling the olfactory test stimulus, which was discarded after being used in one test session for one animal.

Procedure. The subject was placed $25 \mathrm{~cm}$ from the test stimulus and facing it. Data were collected for $5 \mathrm{~min}(300 \mathrm{sec})$. The main dependent variable was the duration of investigation of the test stimulus (number of seconds spent within $5 \mathrm{~cm}$ of the stimulus and facing it). Also measured were frequency of approach to within $5 \mathrm{~cm}$ of the stimulus, latency to first approach, latency from the first approach to the second approach, and frequencies of marking, biting, licking, and elimination. The distance (in centimeters) from the stimulus was recorded every $30 \mathrm{sec}$ throughout the test session.

There were two equal groups of subjects, which were each tested twice. At the end of Session 1, the 30 experimental subjects were given an intraperitoneal (IP) injection of $.03 \mathrm{ml} / \mathrm{g}$ body weight of $.15 \mathrm{M}$ lithium chloride $(\mathrm{LiCl})$. The control subjects received an equivalent dose of physiological saline. Then each subject was returned to its isolation cage, and the open field was cleaned with a $50 \%$ alcohol solution. After a 48-h rest, each subject was retested for Session 2 in the open field with a fresh sample of phenylacetic acid. The $\mathrm{LiCl}$ produced a brief gastrointestinal upset within 15 min of injection, which lasted approximately $1 \mathrm{~h}$.

\section{Results}

The subjects quickly approached the phenylacetic acid and began investigating it in Session 1. During the 5-min test session, most subjects approached frequently and spent several seconds sniffing the test stimulus at each approach. In Session 2, the behavior of the subjects was similar for the control (saline) group, but significantly different for the experimental (lithium) group. The experimental subjects greatly reduced both the frequency of approach and the investigation duration. They appeared to spend more time away from the olfaction stimulus, often sitting in a corner rather than investigating their environment.

For each dependent measure, a 2 by 2 analysis of variance was run on drug (lithium or saline) by time (Session 1 and Session 2), with repeated measures on the last factor. Cicchetti's (1972) extension of the Tukey posttest was used to further test significant interactions. Figure 1 shows the mean ( \pm SEM) duration (seconds) of investigation of the test stimulus by the subjects. For the investigation duration scores, there were highly significant differences for the drug $[F(1,58)=7.13, p<.01]$ and time $[F(1,58)=48.92, p<.001]$ variables and a highly significant Drug by Time interaction $[F(1,58)$ $=68.17, \mathrm{p}<.001]$. The Cicchetti test showed the experimental subject scores in Session 2 to be significantly $(p<.01)$ different from both the experimental subject scores in Session 1 and the control subject scores in Session 2. The control subject scores were not different from Session 1 to Session 2. As is shown in Figure 1, the experimental subjects'
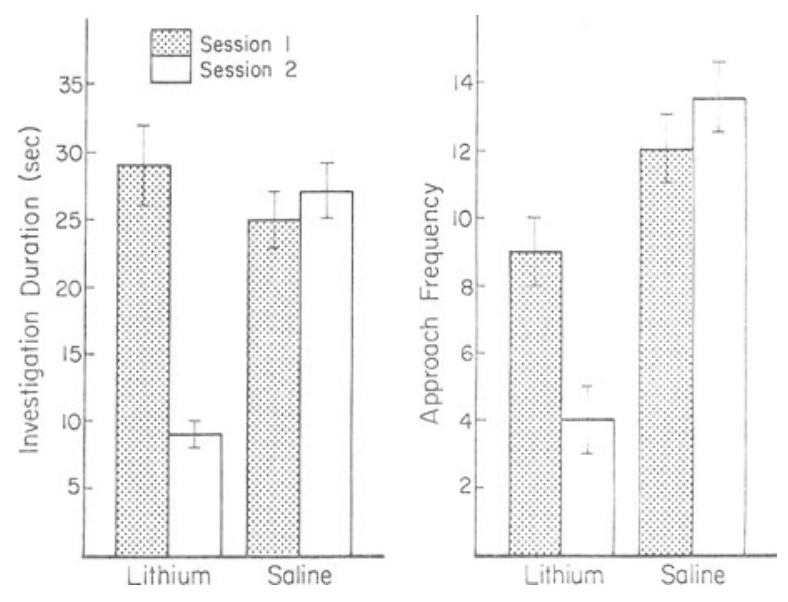

Figure 1. Mean ( \pm SEM) investigation duration (seconds) and mean $( \pm$ SEM) approach frequency for each experimental condition.

investigation duration scores decreased $68 \%$ in Session 2.

Figure 1 also shows the mean $( \pm$ SEM) frequency of approach (to within $5 \mathrm{~cm}$ ) to the phenylacetic acid olfaction source. For frequency of approach, there were again highly significant differences at the $\mathrm{p}<.001$ level for the drug $[\mathrm{F}(1,58)=57.92]$ and time $[F(1,58)=11.03]$ variables and the Drug by Time interaction $[F(1,58)=41.15]$. For the frequency data, the Cicchetti test showed the experimental subject scores in Session 2 to be significantly $(p<.01)$ different from the experimental subject scores in Session 1 and the control subject scores in Session 2. Again, the experimental subjects' frequency-ofapproach scores decreased during Session 2 by $57 \%$.

Figure 2 shows the mean ( \pm SEM) latency (seconds) from first being placed in the open field to the first approach to the phenylacetic acid test stimulus by the subjects. The experimental (lithium) and control (saline) subject scores were significantly different $[\mathrm{F}(1,58)=8.15, \mathrm{p}<.01]$. The control subject scores were similar in both sessions, while the experimental scores nearly doubled in Session 2.

Figure 2 also shows the mean $( \pm$ SEM) latency from the first approach to the second approach to the olfactory test stimulus. For the second latency data, there were significant differences for the drug $[F(1,58)=20.20, p<.001]$ and time variables $[F(1,58)=13.9, p<.001]$. The Cicchetti test found the experimental subject scores in Session 2 to be significantly $(p<.01)$ different from the experimental subject scores in Session 1 and the control subject scores in Session 2.

The overall mean distance from the stimulus source for all subjects was $40.21 \mathrm{~cm}( \pm .97)$. There were no significant differences on either the drug or time factors. Very few markings occurred in this study. Only one subject bit the swab, and he did so only 

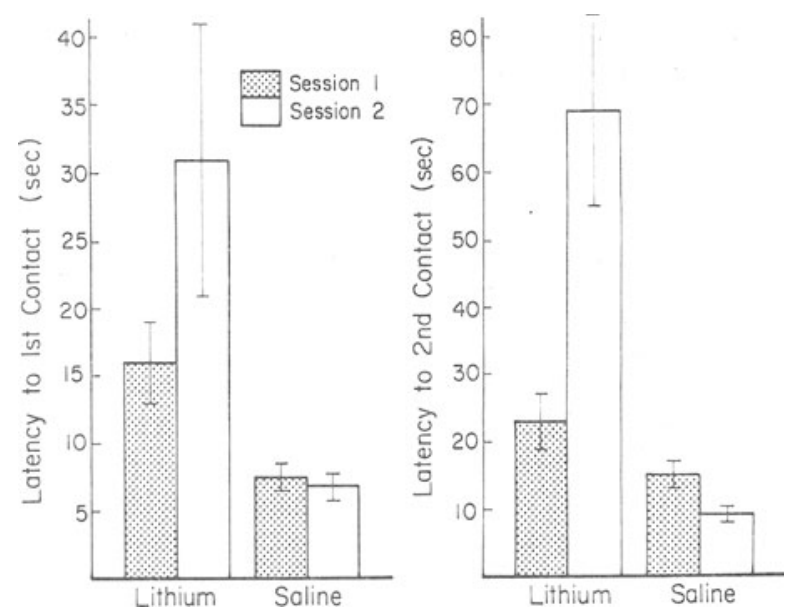

Figure 2. Mean ( \pm SEM) latency to first contact (seconds) and mean $( \pm$ SEM) latency to second contact (seconds) for each experimental condition.

once. No subject was observed licking the test stimulus. Eliminations were very scarce, with a mean of 2.1 per session. These behaviors did not warrant further analysis because of their low frequencies.

\section{EXPERIMENT 2}

It is possible that the aversion demonstrated by the subjects in Experiment 1 was due to variables other than olfaction. To test the possibility that the aversion was not specifically to phenylacetic acid, Experiment 2 examined conditioned aversion to a fresh, clean cotton swab in clay.

\section{Methods}

Thirty adult, experimentally naive male Mongolian gerbils (Meriones unguiculatus), approximately 13 months old at testing, served as subjects. The test stimulus was identical to that used in Experiment 1, with the exception that no phenylacetic acid was used.

The basic procedure for Experiment 2 was identical to that for Experiment 1. All subjects were tested twice (Session 1 and Session 2) with a 48-h rest between them. Half of the subjects were given a $.03-\mathrm{ml} / \mathrm{g}$ body weight IP injection of $.15 \mathrm{M}$ lithium chloride, while the remaining 15 subjects received an equivalent dose of physiological saline immediately after Session 1 .

\section{Results}

As in Experiment 1, the subjects in this experiment quickly approached the test stimulus in Session 1. During the test session, most subjects approached frequently, and spent several seconds sniffing the clean cotton swab at each approach. No subject was observed licking or biting the test stimulus during this experiment. The same results occurred in Session 2, with no significant differences between experimental and control subjects. Thus, the gerbils did not demonstrate an aversion to a fresh, clean cotton swab.
The experimental subjects had a mean investigation duration score of $27.8 \mathrm{sec}$ in Session 1 and $28.9 \mathrm{sec}$ in Session 2. The control subjects showed 25.6 and $29.0 \mathrm{sec}$ of investigation for Sessions 1 and 2, respectively. For the investigation duration scores, there was a significant time effect $[F(1,58)=6.09, \mathrm{p}<.05]$. Inspection of the data shows that investigation time of both experimental and control subjects increased from Session 1 to Session 2.

No significant differences were found for the frequency-of-approach data. The experimental subjects had a mean of 10.8 approaches in Session 1 and 11.2 in Session 2. The control subjects showed a mean of 12.1 approaches in Session 1 and 12.5 in Session 2. There were no significant differences in the scores for either the first or the second latency to approach the cotton swab test stimulus. Overall, the subjects showed a mean of $8.5 \mathrm{sec}$ to the first approach and $14.3 \mathrm{sec}$ from the first contact to the second approach. Both experimental and control subjects behaved similarly in the two test sessions. Likewise, no significant differences were found in the mean distance of subjects to the test stimulus. Overall, the subjects were observed to be $38.0 \mathrm{~cm}$ from the clean cotton swab. Thus the data indicate that the subjects did not show any aversion when the test stimulus was clean cotton swab.

\section{DISCUSSION}

The current research demonstrated that the conditioned aversion paradigm could be extended to olfactory aversion to phenylacetic acid in the male Mongolian gerbil. The results clearly indicated that phenylacetic acid was actively investigated by the gerbils before they were poisoned, but after becoming ill, the substance was avoided by the animals. In Experiment 1, the experimental subjects took longer to initially approach the test stimulus, made fewer approaches, and spent less time investigating the phenylacetic acid during Session 2. The aversion formed was specifically to phenylacetic acid, as demonstrated by Experiment 2, where elimination of this specific odor substance prevented the formation of any aversion.

Although the current research was primarily interested in the olfactory properties of phenylacetic acid, it was possible for the gerbils to physically interact (lick, bite, mark) with the chemical, cotton swab, and clay base. The finding that only one subject bit the test stimulus and only two subjects marked it strongly suggests that the gerbils were responding exclusively to the odor and not to other properties of the test stimulus. In Experiment 2, no biting, licking, or marking was recorded, strengthening the hypothesis that the gerbils were primarily focusing on the phenylacetic acid odor. 
It is interesting that distance from the test stimulus was not a significant variable for the experimental subjects in Experiment 1 . A subject could move a maximum of $50 \mathrm{~cm}$ from the phenylacetic acid test stimulus, and thus the overall mean distance of $40.21 \mathrm{~cm}$ for subjects is relatively large. From observing the subjects, the pattern appeared to be one of rushing up to approximately $3 \mathrm{~cm}$ of the stimulus, sniffing at it for several seconds, and then withdrawing to explore the rest of the open field before returning.

Experiment 2 tested for the possibility that the gerbils were forming an aversion to properties other than the odor of phenylacetic acid. As in Experiment 1, it was found that the subjects did not physically contact the cotton swab. They were, however, curious and tended to actively investigate the cotton swab and clay by sniffing it frequently during both sessions. The finding that even after illness, the experimental subjects continued to strongly investigate the cotton swabs adds support to the suggestion that the aversion produced in Experiment 1 was specifically to the phenylacetic acid odor.

Phenylacetic acid is an active component of the gerbil's ventral gland sebum. However, gerbils communicate olfactorally through urine and feces as well as ventral marking, and it is also possible that gerbils could form aversions to these socially relevant odors. Since the gerbils easily formed an aversion to the odor of this high concentration of phenylacetic acid, the next step might be to associate this odor with social settings. Emmerick and Snowdon (1976) found that hamsters showed longer mating latencies to females coated with phenylacetic acid after they had formed an aversion to the odor. Dominance, aggression, and sexual behavior might possibly be manipulated in this fashion. Since the gerbil quickly learns to avoid a relevant social odor, it is hypothesized that it might also be possible to form an aversion to another intact animal. This possibility is currently being investigated by the author.

\section{REFERENCES}

Cicchetri, D. V. Extension of multiple-range tests to interaction tables in the analysis of variance. Psychological Bulletin, 1972, 77, 405-408.

DAGG, A., \& Windsor, D. Olfactory discrimination limits in gerbils. Canadian Journal of Zoology, 1971, 49, 283-285.

EMMERICK, J., \& SNowdon, C. Failure to show modification of male golden hamsters' mating behavior through taste/odor aversion learning. Journal of Comparative \& Physiological Psychology, 1976, 90, 857-869.

HalPIN, Z. T. Individual differences in the biological odors of the Mongolian gerbil (Meriones unguiculatus). Behavioral Biology, 1974, 11, 253-259.

KanareK, R., Adams, K., \& Mayer, J. Conditioned taste aversion in the Mongolian gerbil. Bulletin of the Psychonomic Society, 1975, 6, 303-305.

Pettijohn, T. F. Reactions of Mongolian gerbils in the presence of urine stimuli. Animal Learning \& Behavior, 1977, 5, 370-372.

Riley, A., \& BARIL, L. Conditioned taste aversions: A bibliography. Animal Learning \& Behavior, 1976, 45, 1-13.

Rudy, J., \& Cheatle, M. Odor-aversion learning in neonatal rats. Science, 1977, 198, 845-846.

Supak, T., Macrides, F., \& Chorover, S. The bait-shyness effect extended to olfactory discrimination. Communications in Behavioral Biology, 1971, 5, 321-324.

Thiessen, D. D., Blum, S., \& Lindzey, G. Scent marking response associated with the ventral sebaceous gland of the Mongolian gerbil (Meriones unguiculatus). Animal Behavior, 1969, 18, 26-30.

Thiessen, D. D., Regnier, F., Rice, M., Goodwin, M., IsaACK, N., \& Lawson, N. Identification of a ventral scent marking pheromone in the male Mongolian gerbil (Meriones unguiculatus). Science, 1974, 184, 83-85.

Wilson, E. O. Chemical communication within animal species. In G. Sondheimer \& J. Simeone (Eds.), Chemical ecology. New York: Academic Press, 1970.

(Received for publication December 19, 1978; revision accepted August 6, 1979.) 